\title{
Museu Eva Hildén em Penedo-RJ: o patrimônio deseja voltar a ser atrativo
}

\author{
Eva Hildén Museum in Penedo-RJ: the heritage wishes to return to be \\ attractive
}

\author{
Diego Uliano RochA \\ ${ }^{a}$ Mestre em Projetos Sociais e Bens Culturais pela Fundação Getúlio Vargas (FGV), \\ Rio de Janeiro. Professor de Turismo do Instituto Federal de Educação, Ciência e \\ Tecnologia do Rio de Janeiro (IFRJ). \\ E-mail: diego.uliano@hotmail.com.
}

\begin{abstract}
O presente artigo busca refletir sobre a relação entre turismo e patrimônio por meio do estudo de caso da trajetória do museu Eva Hildén, no cenário turístico de Penedo-RJ. A região, pertencente ao Sul Fluminense do Estado do Rio de Janeiro, ganhou notoriedade como destinação turística por ser considerada a única colônia finlandesa do Brasil. A expressividade do tema está na relevância desse museu tanto para a atividade turística no município de Itatiaia quanto pela sua função institucional de preservação da memória e identidade da imigração finlandesa na localidade. Trata-se de uma pesquisa documental exploratória feita a partir das seguintes categorias de fontes escritas: bibliografia científica especializada; livros de memória e entrevistas publicadas. De forma complementar, foram utilizados depoimentos de pessoas qualificadas. Com base na reflexão sobre patrimônio, paralelo ao desdobramento do turismo local ao longo da história, analisa-se o desenvolvimento e a atual situação do Bem Cultural na tentativa de responder, resumidamente, os seguintes questionamentos: O que é considerado patrimônio pelo Museu Eva Hildén? Existe alguma relação entre a atividade turística com essa concepção?
\end{abstract}

Palavras-chave: museu Eva Hildén, Penedo-RJ, patrimônio, atrativo turístico.

This article seeks to reflect on the phenomenon of tourism by analyzing the case study of the trajectory of the Eva Hildén museum in the tourist scene of Penedo, state of Rio de Janeiro, Brazil. The municipality gained notoriety as a tourist destination by being considered the only Finnish colony of Brazil. The expressivity of the theme lies in the relevance of this museum, both for the tourist activity in the municipality and for its institutional function of preserving the memory and identity of the Finnish immigration in the locality. This is an exploratory research supported by scientific bibliographies, books of memoirs written by Finnish immigrants and their descendants together with field research. From the reflection on patrimony, parallel to the unfolding of tourism in place throughout history, the development and current situation of the Cultural Good is analyzed.

Keywords: Eva Hildén museum, Penedo-RJ, patrimony, tourist attraction. 


\section{INTRODUÇÃO}

O que se entende por patrimônio? Qual é a sua ligação com os museus e a atividade turística? Esse vocábulo, segundo Reginaldo Gonçalves (2009), é um dos mais empregados no cotidiano para se referir a uma série de elementos que possuem naturezas distintas. Podemos utilizar a palavra no seu sentido econômico, financeiro, artístico, histórico, cultural, ecológico, genético, dentre outros. Pode estar associado aos bens de um indivíduo ou da coletividade. Ser tangível ou intangível (material ou imaterial).

De acordo com o mesmo autor, esta é uma categoria de pensamento universal presente na vida social e mental de qualquer sociedade humana, não se restringindo a sociedades ocidentais. Porém, nem todos os grupos humanos têm no propósito patrimonial a acumulação de bens, como no ocidente. Algumas sociedades, por exemplo, terão por finalidade a sua distribuição. É o caso do ritual Kula, nas ilhas Trobiand - Nova Guiné e do Potlatch, no noroeste americano - Estados Unidos e Canadá.

Na sociedade ocidental, o conceito teve seu sentido advindo inicialmente da sociedade romana, onde seu significado está relacionado a bens e posses derivados da herança familiar. Na Idade Média, passou a ser associado a algo que se respeita, de valor sagrado (DIAS, 2006). No período histórico, conhecido como Renascimento, "pela primeira vez, uma cultura distante mais de um milênio no tempo é considerada ancestral da presente" (FONSEGA, 2005, p. 55). A autora aponta que é neste momento que surge o caráter artístico histórico do termo. A partir de então, procurou-se preservar e recuperar os bens culturais do passado com destaque para as civilizações grega, romana e egípcia.

Na época moderna, durante o processo de formação dos Estados Nacionais, o patrimônio passa a ter agregado a si um valor político. Houve uma apropriação pelo Estado de uma parcela das obras e bens culturais da igreja católica, da nobreza e da monarquia. Esse acervo tornou-se parte dos símbolos dos novos Estados-nação que precisavam ser fortalecidos diante do Antigo Regime (CHOAY, 2006).

Foi também uma estratégia de eliminação das diversidades identitárias existentes a fim de consolidar, por meio da cultura, a invenção da nação (HOBSBAWM, 1984). Desta forma, o patrimônio transformou-se em um símbolo de unidade nacional, com um papel educativo na criação de uma identidade única, e responsável pela difusão dos valores burgueses ascendentes (FONSEGA, 2005).
A partir do início do século XIX, a concepção de patrimônio passou a ser ditada pelo fenômeno da Revolução Industrial, assim como as manifestações artístico-culturais. É nesse período que nasce a atividade turística (BARRETTO, 2011). As viagens ainda eram restritas a um público com poder aquisitivo econômico alto. $\mathrm{O}$ interesse destes deslocamentos temporários era predominantemente relacionado ao conhecimento dos vestígios das civilizações que contribuíram para a formação do mundo ocidental e de monumentos de representação política dos recém-formados Estados-Nação (REJOWSKI et al., 2005).

No início do século XX, o turismo de massas ${ }^{1}$ se desenvolvia na Europa por motivação de distinção social, mas com turistas sem muito conhecimento sobre museologia e seu respectivo acervo. Milhares de pessoas passaram a frequentar esses espaços, porém muitas vezes sem entender o sentido do que era exposto.

Os museus surgiram nesse período como espaços destinados a guardar objetos antigos, no qual se concebiam como "patrimônios". O termo é compreendido no início do século XX como algo encerrado em si mesmo pela importância que teve no passado, sem a possibilidade de ressignificação no presente e futuro (CHOAY, 2006).

O patrimônio era considerado algo único e insubstituível, onde os possíveis danos sofríveis poderiam ser irreparáveis, com possibilidade de perda inestimável. Essa visão fortaleceu a imagem colecionista dos museus, tornando-os como depositários de um passado anterior à produção em massa industrial (CHOAY, 2006).

Ao mesmo tempo, a raridade evocada nos discursos dos museus sobre seus acervos motivou o deslocamento de visitantes para apreciá-los. Isso contribuiu para o desenvolvimento do turismo como um todo. As pessoas com um background ${ }^{2}$ educacional, conforme aponta Pierre Bourdieu (2003), tinham interesse de ver o passado idealizado e de apreciar, como forma de distinção social, os objetos expostos.

1 Termo inicialmente utilizado para classificar o grande número de viajantes europeus de classe média que viajavam para destinos considerados nobres com intuito de criação de um status social (URRY, 2001). Cabe ressaltar que estes fluxos foram interrompidos na Europa nos anos decorrentes da Primeira e Segunda Guerra mundial.

2 O termo é usado na obra de Pierre Bourdieu para designar os indivíduos que possuíram, desde a sua infância, acesso aos principais produtos da cultura erudita humana, resultado de uma educação de qualidade e condições socioeconômicas favoráveis. 
A ideia de patrimônio após o período da Segunda Guerra Mundial é revista. Ele passa a ser entendido por suas dimensões sociais, incorporando representações de outros povos. Transforma-se em um instrumento simbólico de identidades construídas coletivamente no interior da vida social, a partir de conflitos, consensos, contradições, disputas e hierarquias.

O turismo, após uma breve interrupção por conta dos conflitos da Segunda Guerra Mundial, torna-se, conforme coloca Reinaldo Dias (2005), um fenômeno gerador de múltiplos deslocamentos sem precedentes na história da humanidade. As motivações para viajar se diversificaram. Mas as viagens realizadas para deleite do patrimônio e dos museus continuaram a crescer. Paralelo a esse processo, os museus, assim como seu patrimônio, tornam-se campo de batalha dos diversos grupos sociais em torno dos espaços de representação institucionalizados. Eles reivindicam a exposição de suas narrativas, identidades e memórias de acordo com seus pontos de vista (CHAGAS, 2002).

Apesar de patrimônio, museus e turismo serem áreas distintas e independentes, recorrentemente na contemporaneidade, percebe-se um entrelaçamento entre esses elementos, principalmente nos lugares classificados como turísticos. Acredita-se que são campos tensionados. Há uma relação de apropriação, cooperação e disputa política. Nem sempre os resultados dessa combinação são positivos a todo o momento para as partes envolvidas.

A presente pesquisa parte na intenção de analisar, em profundidade, por meio de um estudo de caso, as relações entre patrimônio, museu e turismo no destino turístico Penedo-RJ. O estudo será feito em uma perspectiva histórica a fim de explicar a trama entre finlanidade, patrimônio e atividade turística, assim como as ações dos atores sociais envolvidos na sua construção.

Esta pesquisa é de cunho documental. Seguiu em sua realização uma metodologia que é clássica nos estudos do campo da História. Conforme explica Verena Alberti (2015), é consenso entre os historiadores que o conhecimento sobre o passado não se encontra em estado latente, esperando o historiador para revelá-lo. Os documentos, em si, não expressam uma verdade absoluta. Da mesma forma, também não se encontram naturalmente prontos para dizer como foram os fatos remotos. $\mathrm{O}$ conhecimento sobre o passado ou o pensar historicamente é produzido a partir dos questionamentos feitos às fontes.

Entende-se como fontes "tudo aquilo que, por ter sido produzido pelos seres humanos ou por trazer vestígios de suas ações e interferência, pode nos proporcionar um acesso significativo à compreensão do passado humano e de seus desdobramentos no presente" (BARROS, 2019, p. 1). Cabe acrescentar nessa definição que existem diversos vestígios históricos sobre determinados objetos de pesquisa. Apesar de José D'Assunção de Barros não diferenciar "vestígios" de "fontes", é importante ressaltar que as fontes são também o conjunto de vestígios históricos selecionados pelo historiador para responder suas perguntas de pesquisa.

Assim, diante das possibilidades de ideias possíveis de patrimônio e do método de pesquisa histórico foram feitas as seguintes perguntas para as fontes: O que é considerado patrimônio para os formuladores do museu Eva Hildén? Há alguma relação da atividade turística com essa concepção? Com essas perguntas, pretende-se pensar nas categorias nativas desse conceito pelos atores sociais estudados e se há influência do turismo em sua formulação.

Cabe, dentro do proposto, apontar as fontes que serão questionadas. Procurou-se dar ênfase aos materiais produzidos em primeira mão aos moldes do que caracteriza Clifford Geertz (2008, p. 11). De acordo com o autor, os materiais de "primeira mão" são as interpretações da cultura produzidas pelos nativos. Somente eles podem fazer dessa forma, por se tratar de sua própria cultura. Conforme ele propõe em "descrição densa de culturas", busca-se aqui ver as coisas do ponto de vista do próprio ator social e apresentá-las em formato de narrativa. Logo, procura-se analisar os materiais produzidos pelos imigrantes finlandeses que de alguma forma possuem envolvimento com o Bem Cultural em questão. Em caráter complementar, utilizarei análises acadêmicas de outros pesquisadores sobre o assunto.

\section{A Finlanidade E A CONSTRUÇÃo DO PENEDO TURÍsTICO "FINLANDÊS"}

Penedo localiza-se no sul fluminense do Estado do Rio de Janeiro, no município de Itatiaia. A ocupação dessa região remete aos índios Puris, tribo indígena caçadora e coletora. Eram considerados nômades na região do Vale do Paraíba (DIAS et al., 2015). A pequena tribo foi extinta após a chegada dos colonizadores portugueses. Estes se estabeleceram ali motivados pelo acesso a rotas na área que poderiam levar às minas de ouro e pela qualidade da terra, margeada pelo rio Paraíba do Sul (DIAS et al., 2015) 
No século XIX, por conta do clima e qualidade da terra, além da proximidade dos principais eixos econômicos do país, a região do Vale do Paraíba fluminense tornou-se uma grande produtora cafeeira com uma tímida criação de gado. O uso insustentável do solo para a produção cafeeira levou ao esgotamento e abandono por parte de seus cultivadores, que migraram para o oeste paulista. As terras perderam valor de mercado e passaram a ser vendidas a preços baixos. $\mathrm{O}$ barateamento estimulou o aumento do cultivo de gado, tornando a região uma das maiores produtoras de leite e manteiga do início do século XX (DIAS et al., 2015).

Neste contexto, em 1929, numa antiga fazenda de café, um grupo de jovens imigrantes finlandeses, diante dos conflitos civis que existiam em seu país, viram no Brasil a possibilidade de um novo começo (FAGERLANDE, 2007). Liderados por Toivo Uuskallio ${ }^{3}$, decidiram fundar uma comunidade, baseada na igualdade entre os membros, em busca de um estilo de vida harmônico com a natureza. O preço baixo da propriedade rural, o clima ameno e a existência de uma abundante rede hidrográfica natural foram fatores decisivos para a escolha do lugar (HILDÉN,1989).

A colônia teve seu início em uma fazenda financiada a partir de contribuições dos voluntários que escolheram participar do projeto de imigração. Com isso, surgiu o primeiro núcleo urbano de Penedo, sob a direção dos planos urbanísticos ${ }^{4}$ e sociais ${ }^{5}$ de Toivo Uuskallio (FAGERLANDE, 2007).

O projeto terminou em 1942 devido a problemas financeiros. A falta de dinheiro ocasionou a venda do imóvel pela impossibilidade de pagamento da hipoteca. Entretanto, antes do término do projeto, Toivo Uuskallio trouxe diversas famílias com grande poder aquisitivo, da cidade do Rio de Janeiro, para se hospedarem no casarão onde habitavam os moradores da colônia, com finalidade recreativa (PRAÇA, 2016).

3 Técnico agrícola que lidera e planeja o projeto de fundação de uma colônia finlandesa no Brasil.

4 Uuskallio fez um planejamento para divisão urbanística da Fazenda. Dividiu-a em lotes, ruas e áreas de convívio comum (FAGERLANDE, 2007).

5 Uuskallio pretendia fundar uma sociedade com restrições alimentares, de cunho religioso protestante, baseada em uma filosofia de vida criada por ele mesmo. Acreditava que havia recebido um chamado divino para fundar a colônia no Brasil. Impôs regras severas de comportamento e organização do trabalho na colônia (FAGERLANDE, 2007).
Esse foi um caminho, alternativo à agricultura, de angariar fundos. Pode-se dizer que a iniciativa foi o primeiro passo para divulgação de Penedo como destino turístico e, ao mesmo tempo, uma oportunidade de ganho econômico para os imigrantes, diante da escassez de empregos e meios para sobrevivência (PRAÇA, 2016).

Na década seguinte, a região recebeu um fluxo turístico de maior intensidade, motivado, principalmente, pelo conhecimento dos modos de vida e cultura dos imigrantes finlandeses. Os principais fatores que ocasionaram esse aumento estão relacionados à disponibilidade e hospitalidade dos colonos de receber turistas em suas casas, além de um aumento progressivo na busca dos cariocas pelas férias de veraneio no sul fluminense (GRUZ, 2014).

Desde então, a localidade tem o turismo como a principal atividade de desenvolvimento econômico e social, sendo responsável pela maior parte dos empregos diretos e indiretos como também uma fonte significativa de arrecadação de impostos do município (CRUZ, 2014; JESUS, 2005). O lugar possui atualmente uma população residente estimada em cinco mil habitantes. Este número chega a triplicar nos finais de semana por conta da população flutuante, resultante da atividade turística local (ZOBEL, 2016).

Para Rocha (2019), o principal motivo de busca do destino turístico não é nenhum atrativo material em si. O advento histórico da imigração finlandesa, junto à escolha de uma autoidentificação de pertencimento a esse grupo feita por parte considerável dos negócios relativos ao turismo, consolidou o lugar como casa dos finlandeses brasileiros. O que atrai os visitantes é a ideia de finlanidade. Ela é uma espécie de "aura" que transforma determinados objetos ou locais em elementos que representam a cultura dos imigrantes finlandeses em Penedo. Trata-se de uma espécie de identidade transformada em produto turístico pelos comerciantes.

Esta finlanidade é alvo de disputas entre os habitantes. Ela envolve diretamente o turismo, pois acredita-se que os comércios que possuem essa aura terão mais vendas do que os demais. Percebe-se o uso de diversas formas de elementos simbólicos que possam agenciar consumidores aos respectivos comércios autoidentificados como finlandeses. A escolha desses elementos parece habitar mais no que o senso comum dos visitantes poderia julgar como finlandês do que algo, de fato, perpetuado pelos primeiros imigrantes. 


\section{ORIGEM DO MUSEU: A VINDA DA FAMÍLIA HILDÉN}

A trajetória do objeto de estudo está intimamente ligada tanto a imigração finlandesa local quanto a história da família Hildén. Especificamente, sob a figura de Eva, a responsável por fundar o referido museu sobre o grupo. Toda a narrativa desse tópico é contada a partir de seu livro de memórias intitulado $A$ saga de Penedo: a história da Colônia Finlandesa no Brasil, publicado em 1989. A obra foi financiada pela própria escritora, em uma editora independente ${ }^{6}$. Foi o único livro de memórias escrito pelos imigrantes registrado na Biblioteca Nacional e feito com tiragem expressiva.

Eva veio ao Brasil pela primeira vez, aos seis anos de idade, junto a sua família, na primeira leva de imigrantes finlandeses selecionados por David Pennanen ${ }^{7}$, a pedido de Toivo Uuskallio. A família era vizinha de Uuskallio, na Finlândia. Seu pai - Toivo Suni - era amigo de longa data do idealizador da colônia finlandesa em Penedo; ambos agricultores na terra natal. Suni, com Uuskallio, fez a primeira viagem, representando o grupo, ao Brasil na busca pelo lugar ideal para a fundação do empreendimento colonial.

Os pais de Eva possuíam uma divergência quanto à participação no projeto de imigração. Laura Suni, mãe de Eva e professora, não tinha interesse em sair da Finlândia. Após imigrarem, não conseguiu se adaptar ao afastamento dos entes queridos e às dificuldades da vida nova em terras brasileiras.

A localização da fazenda era geograficamente isolada de outros povoados, contando apenas com uma estação de trem nas proximidades. A linha férrea era a única ligação entre Penedo e a cidade do Rio de Janeiro. Não havia comércio, nem hospitais próximos à fazenda. Existia muito trabalho braçal a ser feito diante das condições da terra e da ausência de infraestrutura regional. Esse é um relato comum presente em outras obras memorialistas sobre o período.

6 Informação dada por Helena Hildén em entrevista. Helena é filha de Eva Hildén e atual responsável pelo museu. Entrevista concedida em 18 de agosto de 2017.

7 David Pennanen era um pastor luterano amigo de Toivo Uuskallio. Ele o ajudou na divulgação das ideias da imigração para o Brasil, na seleção de pessoas para imigrar e na arrecadação de fundos para ajudar manter o projeto.
Esses fatores levaram a uma briga constante entre o casal e muitas idas e vindas do Brasil para Finlândia e vice-versa. Eva Hildén (1989) conta que, ao todo, foram sete idas e vindas até a decisão em definitivo de se estabelecer em Penedo. É um número expressivo diante das dificuldades de locomoção tanto de Penedo para a cidade do Rio de Janeiro como do Brasil para Finlândia. As viagens duravam em média de duas a três semanas, podendo em casos extremos durar até um mês (HILDÉN, 1989).

Numa dentre as sete idas e vindas, Toivo Suni decide, em 1934, ficar definitivamente em Penedo, junto a Uuskallio, na construção da colônia. Laura e seus filhos, Eva e Paavo (irmão de Eva) retornaram à Finlândia. Com a iminência da Segunda Guerra Mundial, Laura e Eva resolvem voltar para o Brasil em 1941, sem Paavo, que iria posteriormente, assim que terminasse o colegial. A Segunda Guerra Mundial e a morte de Paavo na Finlândia fez com que a família toda decidisse, por definitivo, fixar-se em Penedo.

\section{A TRAJETÓRIA TURÍSTICA DO MUSEU}

Neste tópico sobre o museu, as principais fontes de análise para a construção da sua trajetória turística é o livro memorialístico, mencionado no item anterior, escrito por Eva Hildén, e as fontes que documentam o ponto de vista de Helena Hildén, filha de Eva e atual curadora do museu.

O Bem Cultural iniciou-se como elemento secundário de atratividade turística para os negócios da família e tratava, quase exclusivamente, de uma trajetória particular dos envolvidos. Tornou-se, ao longo do tempo, um espaço patrimonializado, que representa o imaginário de uma identidade coletiva. É um caso peculiar, pois, conforme aponta Barretto (2011), o que é mais comum é a apropriação, por parte da atividade turística, do patrimônio.

Na década de1950, o projeto de Toivo Uuskallio havia fracassado. A fazenda Penedo foi vendida e loteada. Porém, uma parte considerável dos imigrantes permaneceu. Eles passaram a viver economicamente da recepção de visitantes em suas residências. Paralelo a isso, surgiram outras atividades ligadas a essa visitação, como a venda de trabalhos manuais, fabricação de doces e tapeçaria. Uma alternativa de sobrevivência frente à carência de empregos e modos de subsistência na região. 
A família Hildén conseguiu no desmembramento da antiga fazenda da colônia finlandesa a casa própria. Assim como os outros descendentes, eles viram na hospedagem e no artesanato para visitantes uma possibilidade de angariar recursos para sobrevivência. Tudo era feito na própria residência. Eles perceberam o grande interesse e curiosidade dos visitantes pela imigração finlandesa que lá houvera (HILDÉN,1989). Helena Hildén Sousa (2017) afirma que sua mãe tinha enorme satisfação em contar sobre sua história e a do grupo imigrante.

Figura 1 - Primeira casa da família Hildén.

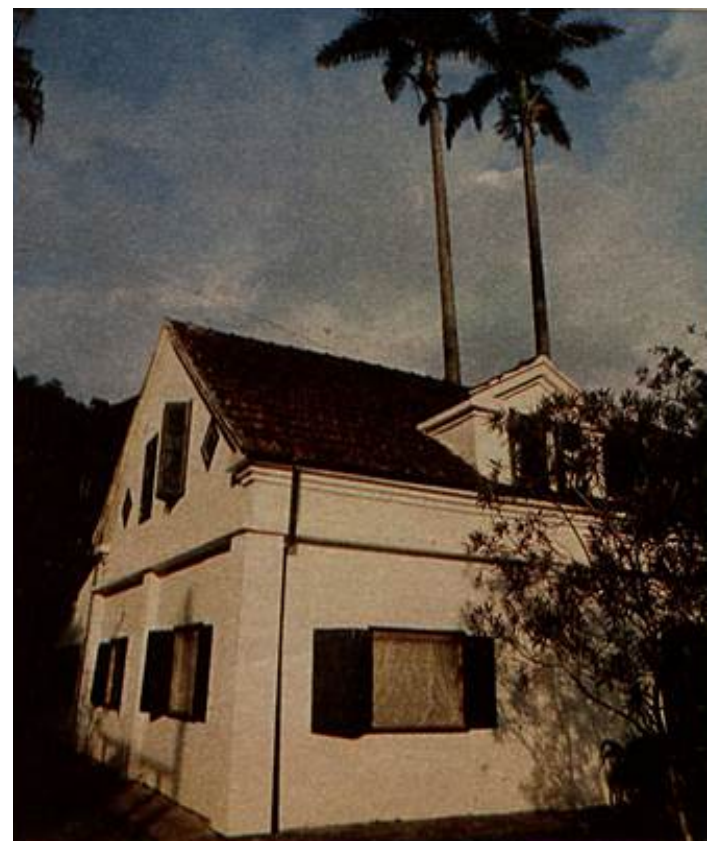

Fonte: Revista Manchete (1979), n. 1400, p. $88^{8}$

Com o passar do tempo, Eva Hildén começou a aumentar seu acervo de peças; sejam elas de origem familiar ou de outros membros que participaram do processo imigratório (HILDÉN, 1989; SOUSA, 2018). Foram levados para sua pequena loja álbuns de família, alguns artefatos pessoais de origem finlandesa e do que restou em sua posse do projeto de Toivo Uuskallio. Segundo a própria Eva, em seu livro de memórias, além de sentir enorme prazer no contar dessas histórias, isso se tornou um diferencial para os seus produtos comercializados, atraindo cada vez mais visitantes para seu ponto comercial.

8 Disponível em: https://bit.ly/319B8vA. Acesso em: 22 nov. 2020
Em 1982, Eva Hildén funda, de maneira simplória, sem apoio governamental, um museu, no lugar da loja, sobre a história de sua própria família. $\mathrm{O}$ acervo do espaço contou inicialmente com seus objetos pessoais e com alguns itens trazidos das diversas viagens que fez de volta a sua terra natal: a Finlândia (HILDÉN, 1989; SOUSA, 2018). A família passou a contar com a venda de ingressos e dos artesanatos como uma fonte de renda, e a hospedagem foi tornando-se um elemento secundário e depois abandonada.

Figura 2 - Eva Hildén e seus artesanatos.

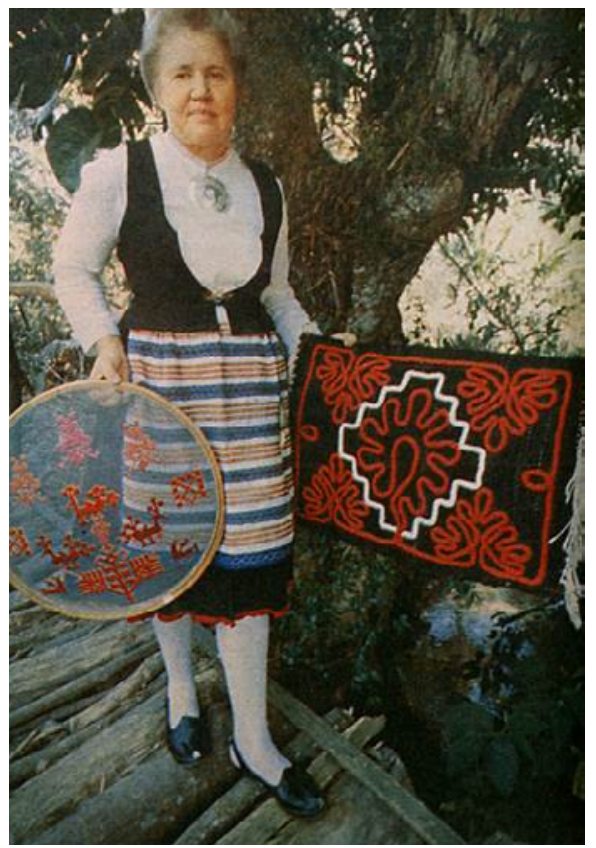

Fonte: Revista Manchete (1979), n. 1400, p. $88^{9}$

Com o passar dos anos, o espaço tornou-se um dos principais atrativos turísticos da região por apresentar a história e a cultura dos imigrantes finlandeses. $\mathrm{O}$ acervo do museu ganhou tamanho frente a doações da comunidade local de descendência finlandesa e de outras pessoas que de alguma forma sentiam-se pertencentes ao grupo (SOUSA, 2018). Esse processo transformou o lugar, que antes era responsável por guardar uma história individual, em um espaço salvaguardor da memória coletiva e dos respectivos objetos que passaram a transmitir, de alguma forma, essa narrativa.

Eva Hildén (1989) dizia, sem sombra de dúvida, que a peça mais valiosa do acervo era ela própria.

9 Disponível em: https://bit.ly/319B8vA. Acesso em: 22 nov. 2020. 
Esse depoimento ganhou ressonância na comunidade, onde todos, mesmo os que não a conheceram, confirmam a estória. Ela era uma anfitriã impecável, sempre muito atenciosa com todos os visitantes, relata Gustavo Praça (2016), jornalista que mora em Penedo há 30 anos. Hildén dava testemunhos sobre todo o passado de aventuras e dramas daquele distante povo desconhecido por nós brasileiros, cercado de mitos em nosso imaginário, salienta Lila de Carvalho (2014) em sua pesquisa de mestrado, mesmo sem ter entrevistado Eva Hildén.
Em 1997 após seu falecimento, os herdeiros do museu decidiram doar para o Clube Finlandês todo o acervo (CARVALHO, 2014). O referido clube destinou um prédio anexo a sua sede para abrigo e exposição. Atualmente, o museu conta com mais de 1000 objetos. Dentre eles, encontramos pertences pessoais da Dona Eva Hildén; peças doadas por famílias de imigrantes finlandeses; algumas vestimentas da Finlândia do início do século XX que ainda são usadas no baile finlandês ${ }^{10}$; os artesanatos produzidos; e obras de arte de colonos e seus descendentes.

Figura 3 - Museu Eva Hildén. À esquerda, entrada do Clube Finlandês.

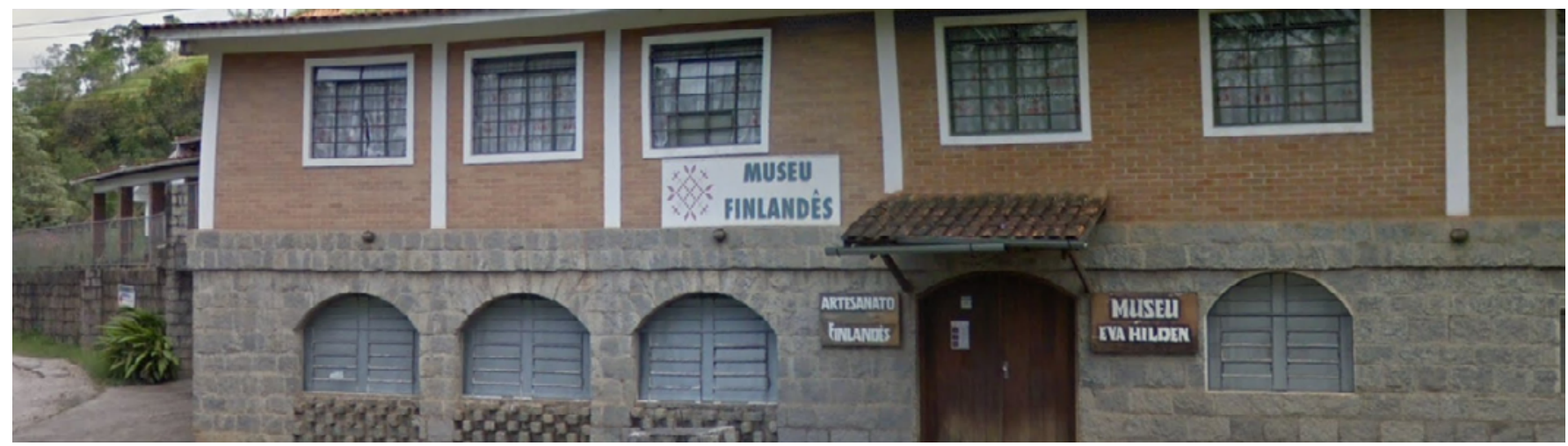

Em parceria com o Clube Finlandês, o museu promove exposições de arte dos colonos descendentes e de temática finlandesa. É também a instituição guardiã dos documentos relativos à imigração dessa etnia na região. Além disso, na parte superior do museu, existe uma biblioteca especializada na cultura finlandesa, com obras raras. A biblioteca conta atualmente com um acervo de aproximadamente oito mil livros.

\section{QuESTÕES DO PRESENTE: DISPUTAS EM TOR- NO DA REPRESENTATIVIDADE FINLANDESA}

\section{NA ARENA TURÍSTICA}

Atualmente, há em Penedo uma diversidade de lugares que usam como apelo para frequência e consumo de seus pontos a ideia de pertencimento à cultura finlandesa, entendida por finlanidade (ROCHA, 2019). Em pesquisa de campo foi constatado que são poucos os estabelecimentos que efetivamente têm alguma ligação com os imigrantes finlandeses estabelecidos em Penedo, ou que de fato trabalham algumas de suas práticas culturais. Dentre eles, está o Museu Eva Hildén.

Segundo Helena Sousa (2018), o museu é o principal salvaguardor não apenas do patrimônio, mas da memória e identidade finlandesa conforme pode-se perceber na entrevista feita por Armele Cruz (SOUSA, 2018 apud CARVALHO, 2014):

Armele: Você acha que as pessoas reconhecem o papel que sua mãe teve ao criar o Museu?

Helena: Sim, se não fosse por este museu, talvez não existisse mais a colônia finlandesa, é o que segura (SOUSA, 2018 apud CARVALHO, 2014, p. 112)

A curadora do museu assim como algumas famílias de imigrantes que se reúnem no Clube Finlandês veem na seleção de objetos realizada por Eva Hildén, e agora, por Helena Hildén Sousa, sob formato museológico, uma marca do que representa ser finlandês em Penedo, a tal da finlanidade. Percebe-se também que o poder

10 O baile acontece no primeiro e no último sábado do mês em Penedo-RJ, no Clube Finlandês, desde a década de 1950. Trata-se de uma festa com danças e comidas típicas da Finlândia do início do século XX. 
público entende tanto o museu quanto o clube finlandês como espaços patrimoniais que salvaguardam esta identidade finlandesa do lugar:

Armele: Como a prefeitura lida com a identidade finlandesa no turismo de Penedo?

Roberta: É uma questão super importante. Nós da prefeitura, Governo Municipal, estamos tentando trabalhar em parceria com as instituições que já lutam pela preservação da história da colonização, que é o caso do Clube Finlândia e o Museu Finlandês. Então, qualquer projeto, qualquer evento, a gente está disposto a apoiar. A prefeitura não teve nenhuma iniciativa para organizar essa questão; até porque depende muito da parceria com o Clube, com o Museu, mas é de fundamental importância, porque com essa colonização é que vieram as primeiras posadas em Penedo. Então essa parte histórica da recepção da hospedagem começou através dos finlandeses, recebendo os familiares, depois os amigos e depois já estavam nessa prática de meios de hospedagem e eles que introduziram a sauna no Brasil. Em Penedo que se iniciou o uso da sauna tão difundido no Brasil. (OLIVEIRA, 2012 apud CRUZ, 2014, p. 96)

No entanto, a questão central para Helena Hildén Sousa parece estar na falta de interesse dos turistas. Por conta disso, o lugar, segundo ela, encontra-se em risco de ter as portas fechadas. O museu é mantido principalmente com os ingressos de visitação turística (SOUSA, 2017).

Para ela, o destino turístico, entende-se aqui os comerciantes e o poder público, deveria de alguma forma contribuir para a manutenção financeira do museu, já que se utiliza em sua divulgação da memória da imigração finlandesa para a atração de turistas. Porém, Helena afirma que não há esta contribuição. E isso pode levar à perda da identidade finlandesa. Percebe-se que a preservação identitária é entendida, por ela, principalmente, como a conservação do museu.

Segundo Helena, essa questão também é um reflexo do novo perfil de visitantes do destino turístico. Ela percebeu que o interesse dos turistas se modificou. Os visitantes têm se preocupado mais em fazer compras e consumir do que efetivamente conhecer a cultura finlandesa e/ou a história da imigração na localidade:

[...] Depois que começaram a construir os shoppings lá em baixo (sic.) piorou a frequência no Museu. O tipo de público que frequenta Penedo mudou. Começaram a vir pessoas que não se interessam por cultura, que só querem passear nas lojinhas (SOUSA, 2018 apud CARVALHO, 2014, p. 110)

Outro fator que surge na fala de Helena para explicar a queda de visitação no museu foi os shoppings em Penedo. Isso fez com que o museu tivesse um declínio brusco de visitação turística, de aproximadamente $50 \%$. Associado a isso está a localização do Bem Cultural. O museu ficou distante do ponto central de concentração dos visitantes do destino, que é no entorno do shopping intitulado "Papai Noel".

Figura 4 - Shopping Casa do Papai-Noel: Pequena Finlândia.

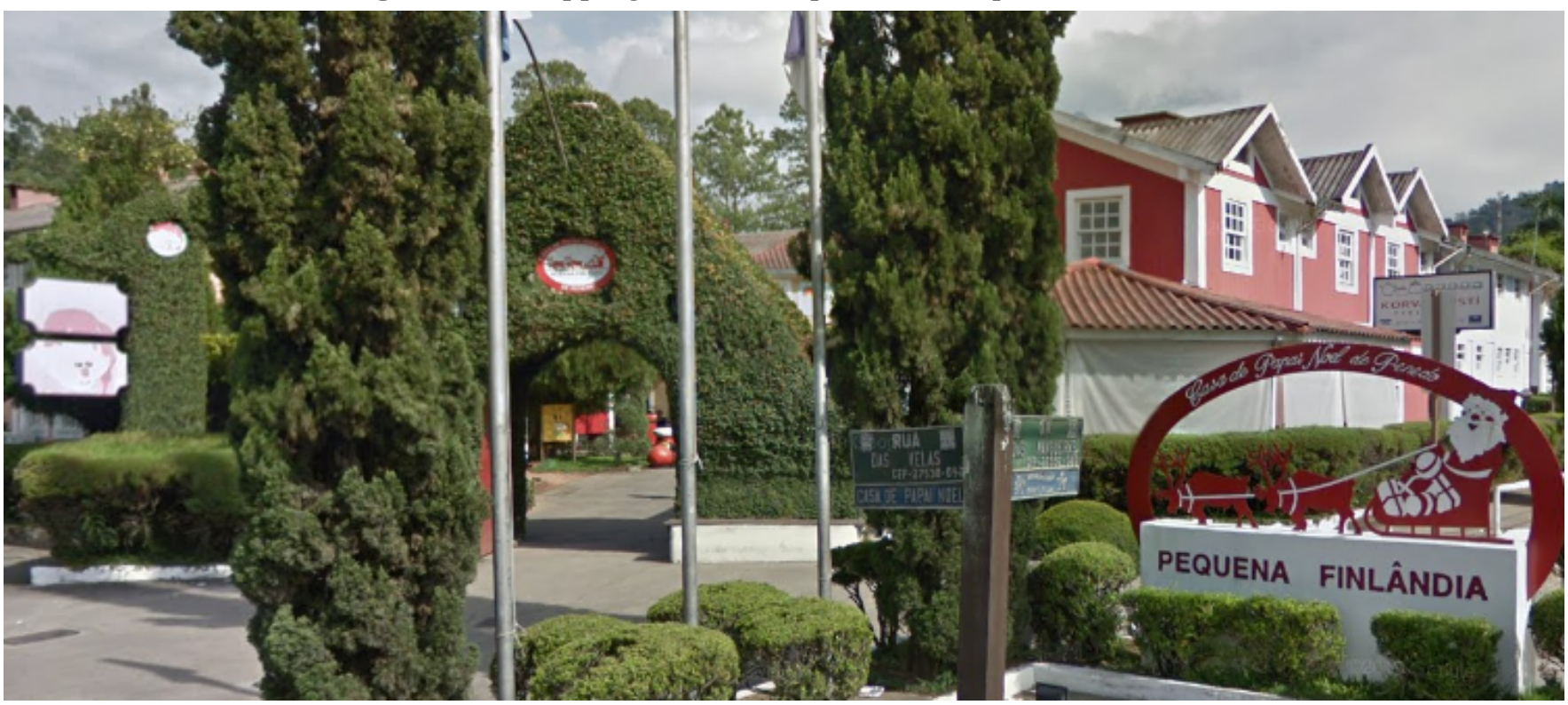


Vale lembrar que antes da construção do Shopping do Papai Noel, a centralidade de visitações em Penedo estava na área na qual se encontra o museu atualmente. Os shoppings, conforme aponta Sérgio Fagerlande (2015), mudaram a espacialidade turística do local, assim como a visão de centralidade turística dos espaços. Com esses empreendimentos o que era central passou a ser periferia. O novo centro começou a ser concentrado em torno dos shoppings, agora distante do museu. As áreas onde estão localizados esses empreendimentos, até o início da década de 1990, eram de visitação remota (FAGERLANDE, 2015).

Helena afirma que existe um projeto para a construção de um novo museu mais próximo da entrada da cidade, em um terreno do Clube Finlandês. Ela acredita que a proximidade maior com o centro comercial possibilitaria o aumento de turistas. Porém, trata-se apenas de planos, pois, no momento, não há recursos.

O museu, assim como os demais lugares que trabalham as questões culturais, promovidos pelos descendentes da imigração finlandesa em Penedo, sentem-se relegados em segundo plano pelos turistas, que preferem visitar e consumir nos shoppings. Esse é o caso do Museu Eva Hildén, expresso na voz de sua curadora.

Por outro lado, os comerciantes, de forma geral, alegam, em conversas obtidas em pesquisa de campo ${ }^{11}$, que a comunidade ligada à imigração finlandesa mostra-se desinteressada em promover ações relacionadas a suas tradições junto aos estabelecimentos, principalmente os que não estejam associados a famílias dos primeiros imigrantes. Isso fez com que os turistas procurassem os shoppings. Eles argumentam que ações culturais desse tipo poderiam ajudar na atração de visitantes para a localidade.

Afirmam não haver nenhum tipo de exclusão. Pelo contrário. O uso da marca "Finlândia" nos comércios é vista por eles como uma contribuição para a preservação da identidade finlandesa local. Alegam, inclusive, que o grupo ligado à imigração não é dono da ideia Finlândia. Portanto, não estão aptos a determinar quem deve usar ou não esse conceito em seus negócios.

\section{CONSIDERAÇÕES FINAIS}

O caso do Museu Eva Hildén é uma das poucas exceções onde as discussões sobre identidade e patrimônio passam a ocorrer a partir do fenômeno do turismo. Em geral, na literatura corrente sobre o assunto, os bens culturais são apropriados pelo turismo. Nesse raro caso, inicialmente ocorre o movimento inverso, o patrimônio se apropria de uma "construção alegórica turística de memória finlandesa" para a preservação e reforço dessa identidade.

Interessante notar que nessa mesma questão, representada pela fala de Helena Hildén, a visitação turística é tão importante quanto o reconhecimento do Bem Cultural como patrimônio, seja pelo poder público ou pelos moradores do entorno. Sem os turistas, a ideia de patrimônio ganha um ar de incompletude.

A utilização dos bens de memória individual de Eva Hildén por ela mesma, para agregar valor aos produtos de sua loja, desenvolveu uma ideia de finlanidade. Isso instigou a participação de outros atores sociais na seleção, apropriação de práticas e objetos na construção da finlanidade, reforçando assim, ao mesmo tempo, os laços do passado histórico e um sentimento de identidade comum a todos que de alguma forma conseguem estabelecer um tipo de vínculo, seja familiar, patriótico, de vivência turística ou ordinária. E propiciou ao grupo uma concepção de patrimônio ligada aos vestígios históricos da imigração finlandesa em Penedo. Para esses imigrantes, a finlanidade é o patrimônio que está expresso em coisas materiais e imateriais.

Porém, a falta de planejamento da atividade turística e a sua desvinculação com os laços culturais desencadeadores da atratividade, na atualidade, têm transformado o lugar em um espaço de disputas entre as famílias dos imigrantes estabelecidas na atividade turística e os recém-chegados comerciantes que não possuem um elo com o passado dessa imigração.

Mesmo não possuindo essa relação com o grupo imigrante, os recém-chegados não veem problema em usar a finlanidade, a seu modo, em seus negócios turísticos. Não a entendem como patrimônio. Para eles, é uma marca que é utilizada como estratégia de marketing para seus produtos. Coisa que parece ser incômoda para os estabelecidos. Principalmente, no que se constrói com a ideia contemporânea de shopping.

11 Os comerciantes entrevistados pediram para omitirem seus nomes no trabalho. 


\section{REFERÊNCIAS}

ALBERTI, V. Ensino de história e fontes históricas. Palestra. In: ENCONTRO NACIONAL DE HISTÓRIA DA UNIVERSIDADE FEDERAL DE ALAGOAS (UFAL), 7., 2015, Maceió. Anais [...]. Maceió: FGV CPDOC. Disponível em: https://bit.ly/2PoMnh2. Acesso em: 25 nov. 2020.

BARRETTO. M. Manual de iniciação ao estudo do turismo. 9. ed. Campinas: Papirus, 2011.

BARROS, J. D. A. Fontes históricas - uma introdução aos seus usos historiográficos. In: ENCONTRO INTERNACIONAL HISTÓRIA \& PARCERIAS, 2 ., 2019, Rio de Janeiro. Anais [...]. Rio de Janeiro: Anpuh, 2019. Disponível em: https://bit.ly/397koK7. Acesso em: 20 nov. 2020.

BOURDIEU, P; DARBEL, A. O amor pela arte: os museus de arte na Europa e seu público. Tradução Guilherme J. F. Teixeira. São Paulo: Edusp, 2003.

CARVAllHO, L. A. P. Os finlandeses de Penedo: uma viagem utópica em direção aos trópicos. 2014. 113 p. Dissertação (Mestrado de Ciências Sociais em Desenvolvimento, Agricultura e Sociedade) - Universidade Federal Rural do Rio de Janeiro, Rio de Janeiro, 2014. Disponível em: https://bit.ly/3f9t7zg. Acesso em: 4 out.2016.

CHAGAS, M. Educação museu e patrimônio: tensão devoração e adjetivação. Rio de Janeiro: IPHAN, 2002.

CHOAY, F. A alegoria do patrimônio. Tradução Luciano Vieira Machado. 4. ed. São Paulo: Ed. Unesp, 2006.

CRUZ, A. M. A influência da etnicidade finlandesa no desenvolvimento do turismo de Penedo. 2014. 96 p. Monografia (Bacharel em Turismo) - Faculdade de Turismo e de Hotelaria, Universidade Federal Fluminense, Niterói, 2014. Disponível em: https://bit.ly/ 3vS745Z. Acesso em: 5 out. 2016.

DIAS, M. J. et al. Resende: passado e presente. Arujá: Espaço Idea, 2015.

DIAS, R. Turismo e patrimônio cultural: recursos que acompanham o crescimento das cidades. São Paulo: Saraiva, 2006.
DIAS, R. Introdução ao turismo. São Paulo: Atlas, 2005.

FAGERLANDE, S. M. R. A utopia e a formação urbana de Penedo: a criação, em 1929, e o desenvolvimento de uma colônia utópica finlandesa no estado do Rio de Janeiro. 2007. 228 p. Dissertação (Mestrado em Urbanismo) - Universidade Federal do Rio de Janeiro, Rio de Janeiro, 2007. Disponível em: https:/ /bit.ly/3rhRFIy. Acesso em: 6 out.2016.

\section{FAGERLANDE, S. M. R. A construção das imagens} turísticas: tematização e cenarização em colônias estrangeiras no Brasil. Rio de Janeiro: Rio Books, 2015.

FONSECA, M. C. L. O patrimônio em processo: trajetória da política federal de preservação no Brasil. 2. ed. Rio de Janeiro: UFRJ, 2005.

GEERTZ, C. A interpretação das culturas. Rio de Janeiro: LTG, 2008.

GONÇALVES, J. R. S. O patrimônio como categoria de pensamento. In: CHAGAS, M. S.; ABREU, R. (org.). Memória e patrimônio: ensaios contemporâneos. 2. ed. Rio de Janeiro: Lamparina, 2009. p. 25-33.

HILDÉN, E. A saga de Penedo: a história da colônia finlandesa no Brasil. Rio de Janeiro: Fotografia Brasileira, 1989.

HOBSBAWM, E. Introdução: a invenção das tradições. In: HOBSBAWM, E.; RANGER, T. (org.). A invenção das tradições. Rio de Janeiro: Paz e Terra, 1984. p. 9-23.

JESUS, G. M. Urbanização turística e a produção do lugar em Penedo. In: BARTHOLO, R.; DELAMORO, M.; BADIN, L. (org.). Turismo e sustentabilidade no Rio de Janeiro. Rio de Janeiro: Garamond, 2005.

OLIVEIRA, R. Entrevista com a Secretária de Turismo de Itatiaia, Sra. Roberta Oliveira, Penedo, 13 nov. 2012. In: CRUZ, A. M. A influência da etnicidade finlandesa no desenvolvimento do turismo de Penedo. 2014. 96 p. Monografia (Bacharel em Turismo) - Faculdade de Turismo e de Hotelaria, Universidade Federal Fluminense, Niterói, 2014. Disponível em: https://bit.ly/ 3vS745Z. Acesso em: 5 out. 2016.

PRAÇA, G. O agricultor filósofo: a colônia finlandesa de Penedo e seu entorno. Itatiaia: Edição independente, 2016. 
REJOWSKI, M. et al. Desenvolvimento do turismo. In: REJOWSKI, M. et al. (org.). Turismo no percurso do tempo. 2. ed. São Paulo: Aleph, 2005.

ROCHA, D. U. Quer conhecer a Finlândia? Vá a Penedo! Uma proposta de roteiro turístico cultural. 2019.190 p. Dissertação (Mestrado profissional em Profissional em Bens Culturais e Projetos Sociais) - Centro de Pesquisa e Documentação de História Contemporânea do Brasil, Fundação Getúlio Vargas, Rio de Janeiro, 2019.

SOUSA, H. H. Entrevista cedida a Diego Uliano

Rocha. Depoimento sobre o Museu Finlandês. 18 ago. 2017.
SOUSA, H. H. O museu Eva Hildén: a memória dos finlandeses em Penedo. In: FAGERLANDE, S. M. R.; Aaltonen, T. (org.). Penedo 90 anos: histórias da colônia finlandesa. Rio de Janeiro: Edicon, 2018.

URRY, J. O olhar do turista: lazer e viagens nas sociedades contemporâneas. São Paulo: Nobel, 2001.

ZOBEL, G. Como uma colônia vegana que virou a "cidade do papai noel". BBC, Rio de Janeiro, 2 ago. 2016. Disponível em: https://bbc.in/31dZLrf. Acesso em: 7 out. 2018. 